\title{
Filosofia e infância: formação docente para atuar em filosofia para/ com crianças
}

\section{Philosophy and childhood: teaching training to work in philosophy for / with children}

\author{
Gizolene de Fátima Barbosa da Silva Cantalice \\ Graduanda na Universidade do Estado do Rio Grande do Norte, Mossoró, Rio Grande do \\ Norte, Brasil. \\ gizolene@hotmail.com - https://orcid.org/0000-0003-2979-5401
}

\author{
Maria Reilta Dantas Cirino \\ Professora doutora pela Universidade do Estado do Rio Grande do Norte, Mossoró, Rio Grande do \\ Norte, Brasil. \\ mariareilta@hotmail.com - https://orcid.org/0000-0003-2362-7271
}

Recebido em 04 de junho de 2020

Aprovado em 11 de agosto de 2020

Publicado em 28 de outubro de 2020

\begin{abstract}
RESUMO
Este artigo tem como objetivo refletir sobre a formação do/a professor/a que irá atuar no Programa de Filosofia para Crianças, idealizado e posto em prática pelo filósofo norte-americano Matthew Lipman, em 1969; e, também, compreender o processo de formação do/a professor/a para atuar na composição de Experiências de Pensamento, proposta do movimento de Filosofia com Crianças desenvolvido e coordenado pelo filósofo e educador argentino Walter Kohan, desde 2007. Para compreender esse processo formativo, nesses dois autores, foram realizadas pesquisas teóricas e práticas através das quais percebemos que em Lipman a formação do professor ocorre de forma sistematizada e rigorosa concebida em quatro estágio: preparo de monitores; estágio de preparação do currículo; estágio modelador; estágio de observação. Enquanto que em Kohan essa formação vai acontecendo no processo colaborativo que envolve a dinâmica relação que passa a ocorrer e aproximar a escola de educação básica e a universidade. Percebemos, ainda, que, mesmo com perspectivas diferentes em suas teorias e práticas de filosofia "para" e "com" crianças, ambos, Lipman e Kohan, defendem a necessidade de uma formação específica para o/a professor/a que irá atuar em tais práticas tendo em vista contribuir para o desenvolvimento do filosofar das crianças desde a educação infantil. Palavras-chave: Filosofia; Crianças; Formação; Professor; Experiências.
\end{abstract}

\begin{abstract}
This article aims to reflect on the formation of the teacher who will work in the Philosophy for Children Program, idealized and put into practice by the American philosopher Matthew Lipman, in 1969; and, also, to understand the process of formation of the teacher to act in the composition of Experiences of Thought, proposal of the movement of Philosophy with Children developed and coordinated by the Argentine philosopher and educator Walter Kohan, since 2007. To understand this formative process, in these two authors, theoretical and practical research was carried out through which we realized that in Lipman, teacher training takes place in a systematic and rigorous way, conceived in four stages: preparation of monitors; curriculum preparation stage; modeling
\end{abstract}


stage; observation stage. While in Kohan, this training is taking place in the collaborative process that involves the dynamic relationship that takes place and brings the basic education school and the university closer. We also realize that, even with different perspectives in their theories and practices of philosophy "for" and "with" children, both Lipman and Kohan defend the need for specific training for the teacher who will work in such practices with a view to contributing to the development of children's philosophizing from early childhood education.

Keywords: Philosophy; Children; Formation; Teacher; Experiences.

\section{Introdução}

O objetivo desse artigo é refletir sobre a formação do/a professor/a que irá atuar no Programa de Filosofia para Crianças - PFpC, idealizado e posto em prática pelo filósofo norte-americano Matthew Lipman, em 1969; e, também, compreender o processo de formação do/a professor/a para atuar na composição de Experiências de Pensamento, ${ }^{1}$ proposta do movimento de Filosofia com Crianças desenvolvido e coordenado pelo filósofo e educador argentino Walter Kohan, desde 2007, através dos estudos e práticas do Projeto de Pesquisa e Extensão "Em Caxias, a filosofia en-caixa?"2.

Nosso envolvimento com o tema decorre das experiências de estudos e práticas em um projeto de pesquisa que discute sobre a importância e necessidade de aproximar a filosofia das crianças. Tais experiências tem nos levado a pensar e intervir em práticas de "experiências de pensamento" com crianças na escola pública na educação básica. Temos nos inquietado com os desafios presentes nesses espaços de atuação, indagamos: qual a formação necessária ao/à docente para atuar em filosofia para/com crianças?

Assim sendo, percebemos que, mesmo com perspectivas diferentes em suas práticas de filosofia "para" e "com" crianças, ambos, Lipman e Kohan, defendem a necessidade de uma formação específica para o/a professor/a que irá atuar em tais práticas tendo em vista contribuir para o desenvolvimento do filosofar das crianças desde a educação infantil. Pretende-se que as reflexões presentes neste artigo venham contribuir na perspectiva de identificarmos possibilidades formativas para os/as professores/as da educação básica, em especial, aqueles/as envolvidos/as com a prática de filosofia para/como crianças.

\section{Filosofia e infância: entrelaços e potencialidades}

A relação entre a filosofia e a infância, historicamente, registra mais aspectos relacionados a uma visão negativa da criança como ser incapaz, vivenciando um estado da vida ainda inacabado, o qual não tem controle das emoções e dos desejos. Por muitos séculos, a criança foi considerada na tradição filosófica como um ser sem razão. Também podemos perceber a característica da infância na perspectiva daquilo que ela virá a ser, no sentido de modelagem de uma educação pensada pelo prisma da possibilidade de que podemos fabricar através das crianças o adulto que desejamos formar.

Exemplos dessa visão negativa podem ser encontrados, de acordo com Kohan (2008), em A República, no Teeteto, de Platão, bem como em várias obras de Aristóteles. Platão defende que as crianças são moldáveis e que se deve cuidar bem da sua educação para que ela se torne o adulto que desejam que ela seja. Nesse contexto, a criança não 
é importante pelo que ela é, mas pelo que ela poderá vir a ser. Nessa visão, cabe à educação a incumbência de modelar esse ser, considerado inferior pela sua pouca idade.

Contudo, há outros registros na trajetória da Filosofia de uma visão mais favorável à criança. Por exemplo, em Heráclito, no fragmento 52, quando esse apresenta a imagem da criança relacionando-a ao tempo-devir, ao tempo aiônico, ao jogo. Nessa analogia, a visão proporcionada por Heráclito aponta para uma criança capaz de jogar: "Nesse jogo o decisivo não é a sorte, mas a capacidade de situar-se na luta, saber bloquear o caminho do adversário e ultrapassar suas defesas." (KOHAN, 2008, p. 11).

Percebe-se nas palavras de Heráclito um outro modo de relação entre a filosofia e a criança. A criança nesse contexto não está no sentido de cronologia, da progressão sequencial - passado, presente, futuro - bebês, crianças, adolescentes, jovens, adultos, velhos -, assim, "[...] não é a criança que se torna adulto, é o devir - criança que se faz uma juventude universal" (DELEUZE; GUATARRI, 1997, p. 60) ou como nos diz Kohan (2004, p. 64), em diálogo com esses autores: "[...] o devir-criança é o encontro entre um adulto e uma criança [...] é uma forma de encontro que marca uma linha de fuga a transitar, aberta, intensa". Isso indica uma outra temporalidade, uma criança/ infância que está dentro do ser humano independentemente de sua idade cronológica.

Nesse sentido, segundo Kohan (2007), o conceito de criança está relacionado ao de infância enquanto tempo. $E$, enquanto tempo, temos a infância majoritária ligada ao tempo cronológico (chrónos) e a infância concebida como minoritária ligada ao tempo aión, enquanto devir. Ambos, chrónos e aión habitam dentro de cada um de nós. "Somos habitantes dos dois espaços, das duas temporalidades, das duas infâncias. Uma e outra infância não são excludentes" (KOHAN, 2007, p. 95).

Quando se discute o conceito de criança relacionado à infância majoritária como chrónos, enquanto uma fase da vida do homem, ver-se que ela foi historicamente negligenciada, predominando uma visão negativa da criança a exemplo da antropologia filosófica de Platão e Aristóteles para os quais "[...] a criança é o que o ser humano tem de pior, na medida em que nela predomina aquilo que a alma humana tem de mais baixo: as emoções, os desejos, as sensações que, nas crianças, seriam dominantes, acima da razão" (KOHAN, 2008, p. 12).

Essa visão negativa da filosofia com relação à infância começa a mudar a partir do século XVI com o pensamento dos filósofos Michel de Montaigne, Rousseau, Schiller, entre outros, e ganha força no século $X X$, especialmente na área da filosofia quando o filósofo norte americano Matthew Lipman começa a se preocupar com a necessidade de uma educação filosófica iniciada, ainda, na educação infantil. Pensando nisso, Lipman elaborou e sistematizou a proposta de um Programa de Filosofia para Crianças - PFpC, com metodologia própria, currículo e formação de professores/as, tendo por finalidade aproximar a filosofia das crianças. Segundo Kohan (2008), essa ideia de Lipman (1990), em aproximar a filosofia das crianças, foi tão inovadora que se tornou um novo campo ou área de interesse da própria filosofia. 


\section{Filosofia para crianças: pensamento, metodologia e formação}

Para Lipman (2008), o pensar é uma habilidade humana que pode ser aperfeiçoada e que as crianças podem, a partir da educação infantil, desenvolver um pensar crítico, cuidadoso e criativo desde que lhe sejam dadas condições adequadas. Para ele, a criança necessita ser despertada para investigações éticas, e isso acontecerá de maneira diversificada para cada criança. Nesse sentido, o PFpC abre possibilidades de inserir as crianças e adolescentes no mundo da filosofia, dando-lhes oportunidades de desenvolver o senso investigativo-dialógico, o qual, de acordo com Lipman (2008), nessa etapa - infância e adolescência - tem grande potencial, mas que precisa ser aprimorado.

Assim, cabe ao/à professor/a possibilitar situações que conduzam a criança a esse aprimoramento do pensamento. Para Lipman (2008, p.33), "Pensar é o processo de descobrir ou fazer associações e disjunções." Nessa perspectiva, o papel do/a professor/a é de fundamental importância para a condução desse processo. Como ferramenta para subsidiar o trabalho de Filosofia para Crianças - FpC do/a professor/a em sala de aula, Lipman (1990) escreveu novelas filosóficas, as quais compõem o currículo do PFpC, que trazem em seus enredos conceitos filosóficos e nas quais os personagens são crianças, pais, professores/as e vizinhos/as vivenciando situações comuns do cotidiano, discutindo temas que fazem parte do dia a dia das crianças que leem essas histórias, fato que contribui para essas crianças se identifiquem com os personagens e também se sintam instigadas a debaterem sobre as temáticas em questão. Lipman (1990), acredita que para conduzir esses contextos, o/a professor/a precisa estar preparado/a para mediar o processo de evolução do pensamento das crianças para que estas possam caminhar do simples ato de pensar para o pensar bem, alcançando o pensamento de ordem superior, que de acordo com Lipman (1990), tem as seguintes características: criticidade, criatividade, flexibilidade e riqueza de recursos.

É na comunidade de investigação que esse pensamento de ordem superior pode ser desenvolvido. Tal comunidade investigativa, através do diálogo filosófico, é a metodologia, proposta porLipman (1990), paraseu PFpC.Assim, asala deaulaéorganizada de forma quetodos/ as integrantes, professor/a e alunos/as se ponham à vista uns dos/as outros/as, formando uma pequena comunidade de investigação onde todos/as se comportam como "co-investigadores" em processo de discussão, reflexão e aprendizado. Vejamos nas palavras de Lipman (1990):

[...] o professor sempre deve assumir responsabilidade suprema por estabelecer aquelas condições que guiarão e estimularão a classe para uma investigação discursiva, mais e mais produtiva, mais e mais autocorretiva. O professor deve estar sempre alerta para uma conduta ilógica entre alunos, exatamente como uma pessoa presidindo uma reunião deve estar alerta a qualquer possível transgressão das regras do procedimento parlamentar. (LIPMAN, 1990, p. 117).

Diante desse contexto percebe-se que o/a docente para atuar no PFpC deve se comprometer com a investigação filosófica e, compreender que ela exige de quem com ela trabalha, esforços cognitivos, voltados para o rigor, para a sistematização, 
para a reflexão, para a análise conceitual e para o esforço de clarificação das ideias. Assim, o/a professor/a precisa estar preparado/a para saber conduzir o pensamento dos/as alunos/as tendo em vista a investigação filosófica do tema proposto. É nessa perspectiva de atuação docente que Lipman (2001) constata a necessidade de uma formação específica para esse/a que irá fazer parte do PFpC. Segundo Cirino (2016), Lipman identifica que a formação docente ofertada nos cursos de licenciaturas, é insuficiente. Acrescenta que nem mesmo a Licenciatura em Filosofia promove a formação necessária para a especificidade do PFpC. Vejamos:

[...] às vezes os professores têm cursos de filosofia da educação [...]. Mas tais cursos são inúteis no que se refere a preparar o professor para incentivar as crianças a pensarem filosoficamente. Um curso universitário de filosofia não prepara o professor para traduzir conceitos e a terminologia da filosofia de uma maneira que as crianças possam entender. (LIPMAN; SHARP; OSCANYAN, 2001, p. 74 apud CIRINO, 2016, p. 84)

Qual será a formação adequada para esse/a professor/a e como ela acontece? Segundo Lipman (1990) "[...] os professores devem ser ensinados exatamente pelos mesmos procedimentos que que eles usarão em sala de aula". (LIPMAN, 1990, p. 45 apud CIRINO, 2016, p.84). Partindo desses pressupostos, a formação do/a docente deverá acontecer de forma que ele/a vivencie na prática o mesmo processo mediador que desenvolverá, posteriormente, com seus/as alunos/as. Segundo Cirino (2016), Lipman propõe que a formação desse/a professor/a aconteça dentro dos Centros de FpC. No Brasil, é criado em 1985, o Centro Brasileiro de Filosofia para Crianças - CBFC.

Assim, os/as professores/as passaram a receber a formação específica para atuar em FpC composta por quatro estágios formativos. Para Cirino (2016), o primeiro estágio formativo, proposto por Lipman, refere-se à formação de uma equipe de professores/as formadores/as, os/às quais irão preparar os/as futuros/as professores/as para atuarem junto às crianças. Assim sendo, esse primeiro estágio é a preparação de monitores/as, "[...] são candidatos os que têm um sólido conhecimento filosófico: professores de filosofia de faculdade, portadores de título em filosofia e aqueles com conhecimento comparável." (LIPMAN, 1990, p. 176).

Nesse sentido, observa-se que são preparados/as profissionais que já tem um conhecimento vasto acerca da filosofia, para que eles/as possam conduzir outros/as professores/as para atuarem com o PFpC. Para que tais candidatos/ as a monitores/as possam ter uma formação qualificada, os/as mesmos/as,

[...] frequentam uma oficina de dez dias, na qual conhecem o currículo, têm a possibilidade de conduzir sessões individuais e discutir assuntos relevantes detalhadamente. [...] Logo após, o futuro monitor passa a ser um 'filósofo em residência' numa sala de aula, por quatro a seis semanas, para adquirir experiência no trabalho com crianças - um pré-requisito para estabelecer credibilidade junto aos professores. Sempre que possível, o aprendiz trabalha junto com um monitor mais experiente antes de se lançar numa carreira independente. (LIPMAN. 1990. p. 177, grifo do autor). 
O segundo estágio, é a preparação do currículo: caracterizado pelo fato de iniciar os estudos ao currículo, em que são divididos grupos de acordo com a faixa etária dos/ as alunos/as, sendo organizados por professores/as de $5^{\circ}$ e $6^{\circ}$ anos e outros de $3^{\circ}$ e $4^{\circ}$ anos, com possibilidades de revezamentos para que os/as professores/as tenham acesso a todas as novelas filosóficas que compõem o currículo de FpC (CIRINO, 2016).

Essa fase da formação tem por objetivo fazer com que os/as docentes em formação experienciem o currículo idealizado por Lipman, de maneira a instigar o pensar individual, coletivo e crítico, ao mesmo tempo, construir diálogos abertos e reflexivos acerca dos diversos temas propostos nas novelas filosóficas que serão trabalhados com as crianças. Nesse contexto, Lipman (1990, p. 178) aponta que "[...] somente se os professores tiverem uma experiência real de uma comunidade de investigação é que poderão promover o desenvolvimento do indivíduo com seus próprios alunos." Já o terceiro estágio, é o modelador que se dará pela etapa de modelação: em que "[...] os monitores devem entrar efetivamente nas salas de aulas dos professores em formação, assumir a lição do dia, e demonstrar ao/à professor/a, com seus próprios alunos, como o monitor trata a matéria." (LIPMAN, 1990, p. 180). Sendo assim, os monitores frequentarão as salas de aulas dos/as professores/as em treinamento e irão atuar de forma prática com os/ as alunos/as.

Por fim, o quarto estágio, é a observação. Segundo Lipman (1990, p. 180), “[...] cerca de seis semanas mais tarde, os monitores voltam à sala de aula para um processo de observação e avaliação da execução do programa por parte dos professores". Nesse período, os/as monitores/as examinam a prática dos/as professores/as em suas salas de aulas e consolidam momentos de trocas de experiências e discussões avaliativas.

No processo avaliativo dos/as docentes em formação, "[...] os treinadores usam listas de critérios para aferir o desempenho do professor, e os professores são encorajados a conhecerem esses critérios para que possam também realizar uma auto-avaliação mais crítica." (LIPMAN, 1990, p. 180). Esses, são os principais pontos no que diz respeito à formação do/as professor/as que irão atuar nas escolas com a FpC. Podemos perceber que em Lipman (1990), o processo formativo é sistematizado com rigor e acompanhamento a fim de garantir a eficácia do PFpC.

Sendo assim, o processo investigativo para atuar em FpC ocorre com o/a professor/a assumindo o papel de facilitador/a, mas sem perder a visão de autoridade de conhecimento. No sentido em que cabe ao/à facilitador/a manter o foco do diálogo, verificar a coerência dos argumentos apresentados e provocar a articulação das ideias. Nesse cenário, as habilidades de raciocínio podem ser aperfeiçoadas, pois que abrangem: "[...] competências em efetuar várias operações dedutivas e indutivas [...] assim como formular perguntas, fornecer razões, elaborar definições, classificar, seriar, exemplificar, e formar conceitos." (LIPMAN, 1990, p. 116).

De acordo com essas considerações, é possível inferir que o/a professor/a na sala de aula de FpC torna-se, por sua formação, um/a mediador/a e organizador/a das condições para que ocorra a comunidade de investigação. Kohan (2008, p. 56-57, grifo do autor) 
destaca que: "[...] o professor facilita as discussões e cuida do cumprimento das regras do jogo na 'comunidade de investigação', mas não tem nenhum papel especial a desenvolver na elaboração das respostas, sempre provisórias e revisáveis". Ou seja, o papel do/a professor/a em sala de aula de FpC é transformá-la numa comunidade de investigação, é mediar e coordenar as respostas dos/as alunos/as, cuidando para que os/as mesmos/as possam fundamentá-las sem confirmar soluções, sem apontar verdades, sem doutrinação, ao contrário, criando as condições para que os diversos pensamentos se manifestem, exercitando a escuta e o respeito mútuo.

\title{
Filosofia com crianças: processo formativo e composição da experiência
}

A partir de 2000, Walter Kohan inicia um outro movimento de problematização e questionamentos acerca do alcance do PFpC de Lipman. Nessa perspectiva observa-se que vai se configurando uma outra alternativa teórica e prática de aproximação entre a filosofia e as crianças, a qual passa a se denominar de filosofia com crianças. Esse movimento que se inicia na Universidade de Brasília e no contexto atual se desenvolve na Universidade do Estado do Rio de Janeiro - UERJ, diferente da FpC de Lipman, não tem um currículo definido e nem uma metodologia específica. Vejamos: "[...] filosofia com crianças compreende a relação entre filosofia e criança de uma forma aberta e constitutiva como uma experiência de pensamento, [...]. Também não tem um programa pré-definido, bem como não assume um método." (CIRINO, 2016, p. 90, grifos da autora).

Nesse sentido, como acontece a formação do/a professor/a que irá atuar nas escolas com a prática de Filosofia com Crianças? Antes, veremos os principais pontos da proposta da Filosofia com crianças" que Kohan (2008) elenca como sendo suas características mais importantes e que, de certa forma, se distinguem, do PFpC:

\begin{abstract}
a) Trabalha exclusivamente com a educação pública; b) é gratuito para os professores e escolas particulares; c) é um projeto teórico e metodológico experimental, não aplica a programas prontos; d) está associado a um projeto de integrado de pesquisa contínua sobre as possibilidades educacionais da filosofia; e) insere-se em escolas com projeto político- pedagógicos que favoreçam a efetiva autonomia do aluno e do professor; $f$ ) trabalha a partir dos projetos em desenvolvimento nas escolas; g) trabalha a formação permanente dos professores, na escola e na universidade; h) envolvem professores e alunos de três cursos: Filosofia, Pedagogia e Psicologia; i) afirma um conceito horizontal, não hierárquico, de interdisciplinaridade; j) integra extensão, ensino e pesquisa na formação de alunos de cursos de graduação da universidade. (KOHAN, 2008, p. 88-89, grifos nossos).
\end{abstract}

A partir desse fragmento, Kohan deixa claro que sua proposta de fazer filosofia com crianças nas escolas é experimental, não tem um programa determinado, nem cursos específicos para formação de professores/as, porém, há uma formação permanente no decorrer do processo que ocorre entre professores/as, escola e universidade. 
Kohan e Olarieta (2012) aprofundam essa discussão defendendo que não há uma forma ou método específico para formação do/a professor/a para atuar em filosofia com crianças. O que percebemos como sendo uma "exigência" é a disponibilidade e abertura para a "experiência do pensamento", para a experiência filosófica sendo considerada como uma relação do sujeito com o saber, dada no encontro com o outro e consigo mesmo, assim sendo é uma atividade que está pautada no permanente processo de busca do saber. "O filosofar é visto aqui como uma experiência, como um trabalho sobre o sentido: sobre o sentido do que somos e do que nos acontece." (idem, ibidem, p.173).

Devemos entender experiência, aqui, no sentido que aponta Larrosa (2014), experiência enquanto acontecimento, algo que se passa com o sujeito e provoca transformação. A experiência como sendo percurso, movimento, um afetar-se, aquilo que nos passa, que nos acontece, e que nos toca. Não o que se passa, não o que acontece, não o que toca. De acordo com Cirino (2016, p. 96), Larrosa (2014) afirma que: "[...] a experiência gera um saber, o saber da experiência, esse saber não é a verdade do que são as coisas, mas o sentido ou o sem-sentido daquilo que nos acontece de forma sempre singular" (LARROSA, 2014, apud CIRINO, 2016, p. 96).

Nesse sentido, o/a professor/a que se dispõe desenvolver a atividade de filosofia com crianças deve compreender que a filosofia e seu ensino é uma possiblidade de experiência de pensamento no sentido proposto por Larrosa (2014), e é nesse sentido que converge o pensamento de Kohan (2009), ao dizer que o ensinar e o aprender filosofia são atividades do pensamento, de modo a afetar a vida daqueles que compartilham.

É, nessa perspectiva, da experiência como acontecimento, como aquilo que nos toca, algo que nos afeta, que Kohan; Olarieta; Wozniak (2012, p. 173), percebem a importância da filosofia nas escolas desde a educação infantil, possibilitando às crianças um espaço para o exercício do pensar, para o filosofar. "O filosofar é visto aqui nesse processo como uma experiência, como um trabalho sobre o sentido do que somos e do que nos acontece".

Por ser um acontecimento, por a experiência ser aquilo que nos toca, que nos acontece, é que ela é própria de cada um/a única e intransferível. Nesse sentido, está aberto à possibilidade de experienciar a experiência enquanto aquilo que nos toca, que nos acontece, na concepção Larrosiana, é necessário um ato de rompimento:

[...] Requer parar para pensar, parar para olhar, parar para escutar, pensar mais devagar, olhar mais devagar, e escutar mais devagar; parar para sentir, sentir mais devagar, demorar-se nos detalhes, suspender a opinião, suspender o juízo, suspender a vontade, suspender o automatismo da ação, cultivar a atenção e a delicadeza, abrir os olhos e os ouvidos, falar sobre o que nos acontece, aprender a lentidão, escutar aos outros, cultivar a arte do encontro, calar muito, ter paciência e dar-se tempo e espaço (LARROSA, 2014, p. 24).

O que Larrosa (2014) nos chama atenção é para um olhar diferenciado, para um olhar "aberto", atencioso e presente. Capaz de nos fazer ver o que normalmente não víamos, de uma educação do olhar. A filosofia com crianças considera que as crianças têm esse olhar 
diferenciado para as coisas e o mundo. Desse modo, poderíamos colocar em questão uma possibilidade de sermos educados/as pelo olhar da criança, da infância, que nos apresenta uma lógica provocadora e atenta às coisas que normalmente nos escapam na observação e vivência de mundo.

Assim, de acordo com Kohan (2012), não tem como se ter um método específico para atuar, experienciar, professor/as e alunos/as em uma experiência de pensamento. $O$ que se tem são relações de abertura e imprevisibilidade que um encontro é capaz de abrir e que vem carregado de possibilidades múltiplas, que em muitos momentos surpreendem ao nos colocar diante de situações novas, modificando todo o movimento que se buscava construir, apontando por direções não planejadas, permitindo que se experimente outros rumos aos quais a novidade da experiência de pensar entre os/as docentes e as crianças instala um novo sentindo.

Conquanto, para a formação do/a professor/a que irá atuar em filosofia com crianças enfatizamos o movimento que ocorre entre a escola de educação básica e a universidade através da prática de filosofia com crianças, o qual vai se constituindo em processo formativo.

\footnotetext{
Depois das experiências com as crianças destina-se um momento com as docentes para refletir sobre as experiências e traçar algumas linhas pelas quais se encaminhará o próximo encontro. Também se realizam reuniões na universidade com algumas das professoras envolvidas. Esses espaços poderiam facilmente ser pensados como espaços de 'formação docente'. (KOHAN; OLARIETA, 2012, p. 173, grifos dos autores).
}

Nesse sentido, não há um método a ser seguido, o que há são possibilidades, aberturas, e assim, a filosofia com crianças se dá no movimento de pensar a experiência, numa relação aberta e imprevista, na qual o/a professor/a vai se formando em processo e transformando-se em conjunto com todos/as. Esse processo exige do grupo ação, reflexão e autorreflexão. Diante disso percebemos que a formação do/a professor/a, na visão de Kohan (2012), é processual, colaborativa e experiencial, pois defende que "a lógica da formação" não pode escapar à lógica da experiência. E dessa maneira, enfatiza que: "O que nos acontece nos afeta particularmente, afeta a relação que temos conosco e com o mundo. Essa relação não pode ser reproduzida, não pode ser passada para outro (o outro não pode atravessar minha experiência) (KOHAN, 2012, p. 173).

Verifica-se também que a formação para atuar em filosofia com crianças acontece através de encontros de formação oferecidos pelo Núcleo de Estudos de Filosofia e Infâncias - $\mathrm{NEFI}^{3}$, a cada dois anos, e no movimento integral da prática de filosofia com crianças nas escolas envolvidas no projeto Em Caxias, a filosofia en-caixa?, como também na inter-relação escola e universidade, a qual tem gerado a continuidade da formação dos/as professores/as envolvidos/as, inclusive com o retorno desses/ as professores/as à universidade em programas de pós-graduação. (CIRINO, 2016).

Assim sendo, não tem como se ensinar uma experiência de pensamento, somente e a partir da própria experiência real, pois que ela é própria, única e intransferível. Vejamos 
que Kohan (2012, p. 175) destaca que não se tem "[...] um método a ensinar às professoras que lhes assegure que, seguindo determinado passos, conseguirão obter por resultado uma experiência de pensamento." Percebe-se que o processo de formação docente acontece de forma singular e imprevisível, ao longo da experiência de pensamento com as crianças e através da maneira como o/a docente vai se entregando e deixando-se tocar pela experiência.

Especificamente, para guiar a ação do docente, Kohan (2012), publica alguns subsídios inspiradores, os quais nomeia de composição, à organização de uma experiência de pensamento com crianças. São eles: uma disposição inicial, que se refere a criar as condições para gerar uma relação afetiva favorável à vivência e convivência no espaço coletivo; vivência de um texto: a escolha do texto deve afetar o/a próprio/a docente, que ele - o texto - tenha potência para incitar o pensamento das crianças; problematização de um texto; esta parte procura instigar perguntas, fazer surgir as afetações provocadas pelo texto; escolha de uma questão: o objetivo desta parte é determinar junto às crianças que pergunta é mais pertinente para a discussão e exploração pelo grupo; diálogo: é o ápice da experiência filosófica, dele participam todos/as os/as envolvidos/as que colocam suas reflexões acerca do texto exposto; para continuar pensando: esta parte é a suspensão da experiência filosófica, possibilita novos começos, se avalia o processo, se recupera o que foi possível pensar até ali e poderá seguir pensando individual ou coletivamente.

Chamam à atenção de que esses passos não são métodos nem tampouco uma receita a ser seguida, mas que eles nascem da própria prática da experiência com crianças no município de Duque de Caxias/RJ, os quais vão sendo, cotidianamente, alterados pela dinâmica e movimento que acontece entre as crianças e os adultos no espaço da filosofia.

Assim, destaca-se a experiência, como a essência para a formação do/a docente para atuar em filosofia com crianças, ela se dá na interrelação entre a universidade e a escola, mediada por estudos teóricos e práticos e no convívio com as crianças, o/a docente é afetado/a de tal forma que eleva a sua capacidade de lidar com as práticas do dia-dia de um/a professor/a que amplia suas visões e suas possibilidades de perspectivas de mundo, causando impactos no seu modo de pensar sua relação com a escola.

Segundo Kohan (2003, p. 224), “[...] o pensar não está dado, ele nasce, se gera, se produz, a partir do encontro contingente com aquilo que nos força a pensar, aquilo que instala a necessidade absoluta de um ato de pensar, de uma paixão de pensar". Nesse contexto, compreendemos o ensino de Filosofia, na perspectiva da filosofia com crianças, como um processo desafiador, não como a exposição conteudista da vida dos/as filósofos/ as, mas como problematização filosófica, como um afetar o modo de vida daqueles/as que a compartilham para que se possa, como Sócrates, provocar a si mesmos e aos outros. Nesse sentido, não há modelos a serem seguidos, nem uma forma para ser copiada.

Com relação ao nosso projeto de pesquisa o seu desenvolvimento acontece tendo como princípio norteador o movimento teórico e prático de filosofia com crianças coordenado por Kohan (2012). A escolha pela prática da filosofia com crianças em detrimento prática da $\mathrm{FpC}$ se deu pelo fato de entendermos que a FpC pressupõe levar algo pronto para dialogar, 
debater com as crianças. Enquanto que a filosofia com crianças traz a ideia de abertura e possibilidades, uma vez que, acreditamos que a relação entre filosofia e crianças é algo que se faz com elas - as crianças como sujeitos do processo. A esse respeito, vejamos as palavras de Cirino (2016),

[...] pensar na filosofia com crianças traz o entendimento que algo que ainda não está pronto, que está em aberto, que elas - as crianças também podem fazer em um espaço de pensamento no qual a infância tem voz própria, numa relação de escuta, atenção e igualdade entre crianças e adultos que constituem e são constituídos nesse fazer que convida à experiência do pensar colocando em questão esse mesmo pensar. (CIRINO, 2016, p. 105, grifos da autora).

$\mathrm{Na}$ prática de filosofia com crianças na escola pública em que nosso projeto atua, realiza-se semanalmente, encontros com crianças da Educação Infantil e Ensino Fundamental para juntos experienciar "experiências de pensamentos" tendo como proposição um texto, uma história, uma gravura, uma música, um vídeo, uma pergunta, ou outro material que tenha potência para instigar nossos pensamentos e inspirar passos para uma composição da experiência de pensamento no sentido proposto por Kohan (2012).

Participam desses encontros, além das crianças, alunos/as dos Cursos de Licenciatura em Pedagogia e Filosofia, bem como professores/as da escola pública na qual o projeto é efetivado. Nesse sentido, a formação dos/as envolvidos/as ocorre em processo contínuo de diálogo entre participantes através da prática/fazeres na escola e dos estudos teóricos, eventos, minicursos e oficinas que ocorrem na relação de aproximação entre a universidade e a escola de educação básica.

\section{Considerações Finais}

Diante do que foi apresentado e discutido, percebemos as significativas diferenças entre a formação do/a professor/a que irá mediar uma Comunidade de Investigação do PFpC, de Matthew Lipman e a formação daquele/a que irá compor uma experiência de pensamento em filosofia com crianças, movimento coordenado por Walter Kohan. Enquanto o/a primeiro/a precisa passar por uma formação sistematizada e rigorosa, o/a segundo/a necessita estar aberto/a à possibilidade de se aventurar à experienciar o pensar em uma experiência de pensamento. Desse modo, sua formação vai acontecendo no processo colaborativo que envolve a dinâmica relação que passa a ocorrer e aproximar a escola de educação básica e a universidade.

Percebemos que os objetivos almejados por Lipman na sua proposta de FpC são próximos aos almejados e definidos por Kohan ao defenderem a aproximação entre filosofia e crianças. Ambos almejam desenvolver, através do diálogo filosófico, que se dá na comunidade de investigação ou na experiência de pensamento, a capacidade filosófica de questionar, argumentar ou pensamento reflexivo das crianças. Considerando, a formação dos/as docentes para atuar em ambas as propostas, os dois autores, mesmo que de pontos 
de vistas diferentes, defendem que a formação dos/as docentes é um dos aspectos que necessita a atenção daqueles/as que desejam elaborar uma prática de aproximação entre a filosofia e as crianças em vista de contribuir com a construção da autonomia dos/as crianças/estudantes.

Nessa perspectiva, a filosofia para/com crianças apresenta-se para além da História da Filosofia, insere-se na sua dimensão criativa, ela é o novo, deve inspirar o surgimento do novo, traz consigo o olhar de espanto, do questionar sobre si mesmos e sobre o mundo, de pensar de outras maneiras. Esses aspectos articulam-se diretamente com a natureza infantil. Portanto, a formação do/a professor/a para atuar tanto na PFpC, inicialmente proposta por Lipman, como na filosofia com crianças vivenciada por Kohan vai depender muito do perfil do/a docente e da experiência que ele/a vai ter com crianças, ela é única e afeta cada um/a de forma diferente. A experiência vivenciada por cada docente será singular, tendo a possibilidade de ser formativa e transformadora de sua relação com a prática de ensinar e aprender na universidade e na escola de educação básica.

\section{Referências}

CIRINO, Maria Reilta Dantas. Filosofia com Crianças: cenas de experiências em Caicó (RN), Rio de janeiro (RJ) e La Plata (Argentina). Rio de janeiro/RJ: NEFI, 2016 (Coleção Teses e Dissertações).

DELEUZE, Gilles; GUATTARI, Félex. Mil Platôs. Capitalismo e Esquizofrenia. Vol.VI. Trad. Suely Rolnik. São Paulo: Editora 34, 1997. (Coleção TRANS).

KOHAN, Walter Omar. Infância: entre educação e filosofia. Belo Horizonte: Autêntica, 2003.

KOHAN, Walter Omar. (Org.). Lugares da infância: filosofia. Rio de Janeiro: D\&A, 2004.

KOHAN, Walter Omar. Infância, estrangeiridade e ignorância. Ensaios de filosofia e educação. Belo Horizonte: Autentica, 2007.

KOHAN, Walter Omar. Filosofia para crianças. 2. ed. Rio de Janeiro: Lamparina, 2008.

KOHAN, Walter Omar. Filosofia: o paradoxo de aprender e ensinar. Belo Horizonte: Autêntica, 2009.

KOHAN, Walter Omar. Palavras, passos e nomes para um projeto. In: KOHAN, Walter Omar; OLARIETA, Beatriz Fabiana. (Orgs.). A escola pública aposta no pensamento. Belo Horizonte: Autêntica, 2012. p. 13 - 49. (Coleção Ensino de Filosofia).

KOHAN, Walter Omar; OLARIETA, BEATRIZ Fabiana. (Orgs.). A escola pública aposta no pensamento. Belo Horizonte: autenticam 2012. (Coleção Ensino de Filosofia).

KOHAN, Walter Omar; OLARIETA, BEATRIZ Fabiana; WOZNIAK, Jason. Repensando, com outras vozes, os sentidos do filosofar. In: KOHAN, Walter Omar; OLARIETA, Beatriz Fabiana. (Orgs.). A escola pública aposta no pensamento. Belo Horizonte: Autêntica, 2012. p. $169-239$.

LARROSA, Jorge. Tremores: escritos sobre experiência. Tradução de Cristina Antunes, João Wanderley Geraldi. Belo Horizonte: Autêntica, 2014. 
LIPMAN, Matthew. A filosofia vai à escola. Tradução de Maria Elice de Brzezinski Prestes e Lúcia Maria Silva Kennedy. São Paulo: Summus, 1990. (Novas buscas em educação; v. 39).

LIPMAN, Matthew; SHARP, Ann Margaret; OSCANYAN, Frederick S. A filosofia na sala de aula. Tradução de Ana Luiza Fernandes Falcone. São Paulo: Nova Alexandria, 2001.

LIPMAN, Matthew. O pensar na educação. Tradução de Ann Mary Fighiera Pérpetuo. 4.ed. Petrópolis-RJ: Vozes, 2008.

\section{Notas}

1 Termo utilizado por Kohan (2012) para se referir às experiências que acontecem dentro do projeto de extensão "Em Caxias, a filosofia en-caixa?".

2 A Filosofia com crianças coordenada por Kohan, se desenvolve, especialmente, através das práticas de filosofia com crianças na escola pública no município de Duque de Caxias/RJ, desde o ano de 2007, com o Projeto de Pesquisa e Extensão Filosofia: Em Caxias, a filosofia en-caixa?, através do Núcleo de Estudos Filosofias e Infâncias - NEFI. (KOHAN; OLARIETA, 2012).

3 Para maiores esclarecimentos, acessar: www.filoeduc.org.

\section{Correspondência}

Gizolene de Fátima Barbosa da Silva Cantalice - Manoel Dantas, 1405-A, Penedo, CEP: 59300000, Caicó, Rio grande do Norte, Brasil.

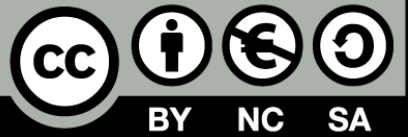

This work is licensed under a Creative Commons Attribution-NonCommercial 4.0 International (CC BY-NC 4.0) 